\title{
Satisfacción laboral de los trabajadores con discapacidad
}

\author{
Ainhoa Durá \\ Galant Garbitasuna \\ S.L.U. Grupo Gureak \\ <adura@grupogureak.com>

\section{Karmele Salaberría} \\ Dpto. de Personalidad, Evaluación y Tratamientos Psicológicos \\ Universidad del País Vasco / Euskal Herriko Unibertsitatea
}

Honako ikerketa deskriptiboan, Gipuzkoako Gureak Taldeko garbiketara dedikatzen den enpresako

(Galant Garbitasuna S.L.U.), ezgaitasuna duten 328 langileen, lan-gogobetetze inguruko datuak aurkezten dira. Ikerketan, langileen sexua, lan kategoria, ezaugarri sozio-demografikoak eta lan profila kontutan izanik, lanaren inguruko gogobetetze mailaren azterketa egin da. Emaitzek ondorengoa azaltzen dute: lan gogobetetzea ertaina-altua da, emakumezkoek gogobetetze altuagoa aurkezten dute eta kategoria laboral altua izateak ez du gogobetetze maila altuagoa ekartzen.

\section{HITZ GAKOAK:}

ezgaitasuna, lana, lan gogobetetzea, gizarteratzea, enplegu-zentro berezia.
En el presente estudio descriptivo se ofrecen datos sobre el nivel de satisfacción laboral de 328 trabajadores/as con discapacidad del sector de la limpieza en la empresa Galant Garbitasuna, S.L.U., del Grupo Gureak de Gipuzkoa. Se describen las características sociodemográficas y el perfil laboral, así como el nivel de satisfacción general, y también por sexo y categoría laboral. Los resultados muestran que la satisfacción general es medio-alta, que las mujeres están más satisfechas con su trabajo y que niveles más altos de categoría laboral no suponen mayor nivel de satisfacción.

\section{Palabras Clave:}

discapacidad, trabajo, satisfacción laboral, integración en la sociedad, centro especial de empleo. 


\section{Introducción}

Deficiencia, discapacidad y minusvalía son tres términos que habitualmente se utilizan como equivalentes, pero que tienen significados diferentes. La Organización Mundial de la Salud (2000) define cada uno de ellos en la Clasificación Internacional de Deficiencias, Discapacidades y Minusvalías (CIDDM-2):

- Deficiencia: "es toda pérdida o anomalía de una estructura, o función psicológica, fisiológica o anatómica”. Así, según la CIDDM y desde el punto de vista de la salud, "una deficiencia es toda pérdida o anormalidad de un órgano o de la función propia de éste". Así, pueden darse deficiencias del órgano de la visión, del de la audición o del lenguaje, entre otros.

- Discapacidad: “es toda restricción o ausencia (debido a una deficiencia) de la capacidad de realizar una actividad de la forma, o dentro del margen, que se considera normal para un ser humano". La discapacidad es consecuencia de una deficiencia. Así, dependiendo del tipo de deficiencia, se podría producir una discapacidad de la comunicación o de la conducta.

- Minusvalía: “es una situación de desventaja para un individuo determinado, debido a una deficiencia o a una discapacidad, que limita o impide el desarrollo de un rol que es normal en su caso, en función de la edad, sexo y factores culturales y sociales". La situación de desventaja a la que alude la OMS se manifiesta en la relación entre la persona y su entorno. Así, las minusvalías pueden ser de orientación, de movilidad o de integración social, por ejemplo.

Las personas con deficiencias, discapacidades 0 minusvalías son personas vulnerables, ante las cuales el proceso de rehabilitación se plantea, según la CIDDM-2, como una realidad con dos vertientes complementarias: la médica y la psicosocial. La rehabilitación médica tiende a reducir las deficiencias debidas a las diversas lesiones y a restaurar un funcionamiento óptimo de la persona. La rehabilitación psicosocial sigue un camino más educativo y persigue que la persona viva tan plenamente como sea posible dentro de su ambiente. Los problemas de empleo, las dificultades económicas y las preocupaciones interpersonales pueden ser enormes para las personas vulnerables (Nezu, Nezu y DelliCarpini, 1997).

En la rehabilitación psicosocial, la integración supone crear redes familiares, sociales, laborales y comunitarias que permitan sentirse útiles a las personas con discapacidad. La satisfacción con la vida se deriva del bienestar físico, social y laboral (Verdugo, 1998). Para la integración, contar con un trabajo que organiza el día y hace sentirse útiles a las per- sonas es esencial. Sin embargo, no es fácil integrar en el ámbito laboral al colectivo de discapacitados. La Ley 13/1982, de Integración Social y Laboral de Minusválidos (BOE, 30/04/82), obliga a reservar un $2 \%$ de la plantilla para la población activa con alguna discapacidad a todas las empresas con más de 50 empleados, pero según un informe de la UGT en Cataluña, esta reserva no se alcanza ni en el $0,8 \%$ de los casos.

En 1972, la Asociación Guipuzcoana Pro Subnormales (actualmente Atzegi) creaba en San Sebastián y en Bergara los primeros centros de trabajo para la atención laboral de las personas adultas con discapacidad intelectual. Era el fruto de más de una década prestando atención a las familias, a los niños con retraso mental, y trabajando también en el ámbito de la educación. El siguiente paso, inevitable, era lograr el acceso de los deficientes mentales al mundo laboral. A pesar de que el derecho a un trabajo era evidente, la posibilidad de que las empresas privadas contratasen a estos hombres y mujeres era muy difícil. La solución adoptada en ese momento fue la creación de unos talleres protegidos en los que se diera continuidad al esfuerzo que se estaba dando en la pequeña red de centros de educación especial ya en marcha. Los primeros talleres de trabajo protegido constituyeron el germen de la futura evolución hacia alternativas laborales y ocupacionales de mayor envergadura económica y empresarial.

De este modo, en 1975 Talleres Protegidos Gureak S. A. se constituyó con personalidad jurídica propia. Se trata de una entidad social con ámbito de actuación en el territorio histórico de Gipuzkoa y cuyo objetivo, tal como se indica en el art. 2 de sus estatutos, es "la actividad de educación, rehabilitación y recuperación de minusválidos, a fin de lograr su integración laboral y social". El colectivo al que fundamentalmente se dirige la acción de Gureak es la población con discapacidad intelectual adulta del territorio histórico de Gipuzkoa. Actualmente, Gureak diversifica sus de actividades en distintos ámbitos laborales ${ }^{1}$.

El colectivo al que iba dirigido el trabajo de Gureak, personas con discapacidad intelectual, se ha ampliado también a otros colectivos de personas con discapacidad física, sensorial y enfermedad mental. La experiencia de Gureak demuestra que, en cualquiera de los sectores de la actividad económica (industria, agricultura, servicios), se pueden encontrar tareas, actividades y productos susceptibles de ser elaborados por personas afectadas por una deficiencia, por grave que ésta sea. Sin embargo, existen pocos estudios que den a conocer el nivel de satisfacción laboral en personas con discapacidad.

1 Para más información, puede consultarse la sede electrónica de la entidad (http://www.grupogureak.com/). 
Los que existen se centran en personas con discapacidad física o discapacidad intelectual, y comparan a personas con discapacidad intelectual empleadas y sin empleo (Flores et al., 2010), o bien analizan el proceso de inserción laboral, mediante empleo con apoyo, de personas con discapacidad intelectual (Alomar y Cabré, 2005).

En estos momentos, el objetivo de Gureak es no sólo dar trabajo al colectivo de personas con discapacidad, sino mejorar sus servicios y conocer también la percepción y la satisfacción de los trabajadores del colectivo. El estudio que se presenta tiene ese fin.

\section{Metodología}

\subsection{Objetivos}

La investigación se desarrolla en la empresa Galant Garbitasuna, S.L.U., dedicada a la limpieza industrial y perteneciente al Grupo Gureak, y se plantea los siguientes objetivos:

- Conocer a los y las trabajadoras: perfil sociodemográfico, tipo y porcentaje de minusvalía, características laborales (tipo de tarea, lugar donde se realiza, categoría laboral, tipo de contrato y años en la empresa).

- Conocer el nivel general de satisfacción laboral de los y las trabajadoras.

- Conocer el nivel de satisfacción laboral de los y las trabajadoras en función de diversas variables: sexo, categoría laboral y tipo de minusvalía.

\subsection{Hipótesis}

El estudio parte de cuatro hipótesis:

- El nivel de satisfacción laboral será medio-alto.

- No existirán diferencias significativas en la satisfacción laboral en función del sexo.

- Existirán diferencias significativas en la satisfacción laboral entre los y las trabajadoras de diferentes categorías, a favor de las más altas.

- Existirán diferencias significativas en la satisfacción laboral entre los diferentes colectivos con diferentes discapacidades, a favor de las personas con discapacidad física y en contra de las personas con enfermedad mental.

\subsection{Participantes}

De las 546 personas de la plantilla de Galant, fueron encuestadas 328 , es decir el $60 \%$. La proporción de la muestra encuestada respecto de la plantilla es adecuada, tanto en cuanto al tipo de discapacidad como a la sección en donde trabajan (tabla 1).

Tabla 1. Tipo de discapacidad

\begin{tabular}{l|c|c|c|c}
\hline \multirow{2}{*}{} & \multicolumn{2}{|c|}{ Encuestados } & \multicolumn{2}{c}{ Plantilla } \\
\cline { 2 - 5 } $\begin{array}{l}\text { Discapacidad } \\
\text { intelectual }\end{array}$ & 98 & 29,87 & 156 & $\mathbf{N}$ \\
\hline $\begin{array}{l}\text { Enfermedad } \\
\text { mental }\end{array}$ & 78 & 23,78 & 125 & 22,89 \\
\hline $\begin{array}{l}\text { Discapacidad } \\
\text { física }\end{array}$ & 106 & 32,31 & 192 & 35,16 \\
\hline $\begin{array}{l}\text { Discapacidad } \\
\text { sensorial }\end{array}$ & 46 & 14,02 & 73 & 13,36 \\
\hline Total & 328 & - & 546 & - \\
\hline
\end{tabular}

Fuente: Elaboración propia.

También se guardaron las proporciones respecto al lugar de trabajo de la muestra encuestada (tabla 2 ).

Tabla 2. Lugar de trabajo

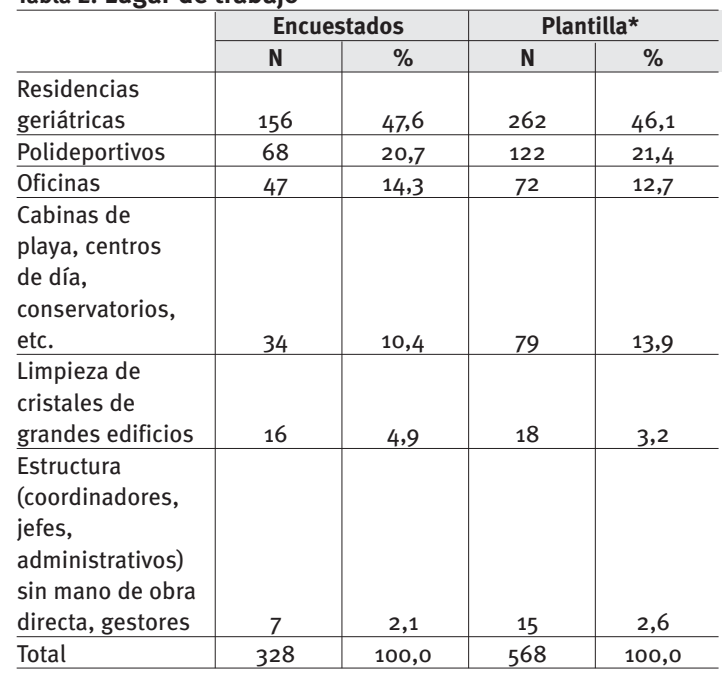

* Incluye personal con y sin discapacidad.

Fuente: Elaboración propia.

\subsection{Metodología de evaluación}

Para evaluar la satisfacción laboral, se diseñó una encuesta que contempla diversos aspectos del trabajo realizado en la empresa. Fue elaborada por los responsables de las diferentes empresas de servicios, y se fue adaptando para facilitar la compresión e ir recogiendo diferentes aspectos relacionados con el desempeño laboral y las relaciones laborales. La encuesta consta de 35 preguntas, que se responden en una escala del 1 al 4, para valorar, de menor a mayor, la satisfacción en diferentes ámbitos: general, condiciones materiales y laborales, relaciones laborales, promoción y desarrollo profesional, organización, información y comunicación. A mayor puntuación, mayor satisfacción laboral. También se añadieron dos preguntas abiertas: “¿cómo mejorarías el trabajo de 
tu encargado/a?” y “¿cómo mejorarías la empresa?”. Se recogieron asimismo datos sociodemográficos, del tipo y porcentaje de minusvalía y variables relacionadas con el trabajo: tipo de tarea, lugar, categoría laboral, tipo de contrato y años en la empresa.

\subsection{Procedimiento}

Se elaboró una carta informativa sobre el trabajo que se iba a realizar, junto con una hoja de consentimiento. En la carta, se explicaba el objetivo del trabajo y la confidencialidad de los datos recogidos, y se recogió la hoja firmada a modo de consentimiento informado. La encuesta fue administrada por la empresa Gupost, del Grupo Gureak, que formó para ello a cinco encuestadoras. Se escogieron cinco días laborales en los que estas mujeres acudieron a diferentes centros, en diferentes turnos de trabajo, y encuestaron al personal que se encontraba allí en ese momento, de modo individual y guardando el anonimato.

\section{Resultados}

Para el análisis de resultados, se utilizó el progra-

Tabla 3. Estado civil (porcentajes y medias) para variables cuantitativas y análisis de chi cuadrado para variables cualitativas. Se han realizado también análisis comparativo de medias y de varianzas en las variables cuantitativas.

\subsection{Características sociodemográficas}

La muestra (328 personas) estaba formada prácticamente por la misma cantidad de hombres y mujeres: 163 hombres $(49,7 \%)$ y 165 mujeres (50,3\%). La media de edad era de 45,33 años (desviación típica: $9,2)$, con un rango de entre 21 y 66. La mayoría de los/as trabajadores/as ( $41,2 \%)$ se situaban en una franja de edad de 41 a 50 años. Más de la mitad decía estar soltero/a (53,4\%), el 29,6\% afirmaba estar casado/a o ser pareja de hecho, y el 11,3\% estaba separado/a o divorciado/a. Por lo que respecta a las diferencias de sexo, entre los hombres había un mayor porcentaje de solteros (32\%); pero entre las mujeres, un $8 \%$ estaban separadas o divorciadas, frente a un $3 \%$ de los hombres.

Un $61,9 \%$ de la muestra no tenía hijos, frente al $38,1 \%$ que sí los tenía. El porcentaje de mujeres con hijos era más alto que el de hombres en la misma situación: un $25 \%$ frente a un $12 \%$ (tabla 3 ).

\begin{tabular}{|c|c|c|c|c|c|c|c|}
\hline \multirow[t]{2}{*}{ Estado civil } & \multicolumn{2}{|c|}{ Total } & \multicolumn{2}{|c|}{ Hombres } & \multicolumn{2}{|c|}{ Mujeres } & $\chi^{2}$ \\
\hline & $\mathbf{N}$ & $\%$ & $\mathbf{N}$ & $\%$ & $\mathbf{N}$ & $\%$ & \multirow{7}{*}{$326,32(4)^{\star}$} \\
\hline Solteros & 175 & 53,4 & 105 & 32 & 70 & 21,4 & \\
\hline Casados / pareja de hecho & 97 & 29,6 & 40 & 12,2 & 57 & 17,4 & \\
\hline Separados/divorciados & 37 & 11,3 & 10 & 3,0 & 27 & 8,3 & \\
\hline Viudos & 8 & 2,4 & 2 & 0,6 & 6 & 1,8 & \\
\hline No contestaron & 11 & 3,4 & 6 & 1,8 & 5 & 1,6 & \\
\hline Total & 328 & 100,0 & 163 & - & 165 & - & \\
\hline
\end{tabular}

* $p<0,05$.

Fuente: Elaboración propia.

Tabla 4. Número de hijos

\begin{tabular}{|c|c|c|c|c|c|c|c|}
\hline \multirow[t]{2}{*}{ № de hijos } & \multicolumn{2}{|c|}{ Total } & \multicolumn{2}{|c|}{ Hombres } & \multicolumn{2}{|c|}{ Mujeres } & $\chi^{2}$ \\
\hline & $\mathbf{N}$ & $\%$ & $\mathbf{N}$ & $\%$ & $\mathbf{N}$ & $\%$ & \multirow{6}{*}{$68,37(3)^{\star}$} \\
\hline No tiene & 203 & 61,9 & 116 & 35,4 & 77 & 23,5 & \\
\hline 1 & 47 & 14,3 & 17 & 5,2 & 30 & 9,1 & \\
\hline 2 & 60 & 18,3 & 23 & 7,0 & 37 & 11,3 & \\
\hline$>2$ & 18 & 5,5 & 2 & 0,6 & 16 & 4,9 & \\
\hline Total & 328 & 100,0 & 163 & 100,0 & 165 & 100,0 & \\
\hline
\end{tabular}

* $p<0,001$.

Fuente: Elaboración propia.

Tabla 5. Forma de convivencia

\begin{tabular}{|c|c|c|c|c|c|c|c|}
\hline \multirow[t]{2}{*}{ Forma de convivencia } & \multicolumn{2}{|c|}{ Total } & \multicolumn{2}{|c|}{ Hombres } & \multicolumn{2}{|c|}{ Mujeres } & $\chi^{2}$ \\
\hline & $\mathbf{N}$ & $\%$ & $\mathbf{N}$ & $\%$ & $\mathbf{N}$ & $\%$ & \multirow{9}{*}{$348,65(5)^{\star}$} \\
\hline Pareja o hijos & 123 & 37,5 & 77 & 23,4 & 79 & 24,1 & \\
\hline Padres o hermanos & 128 & 39,0 & 44 & 13,4 & 51 & 15,6 & \\
\hline Solo/a & 30 & 9,1 & 19 & 5,8 & 11 & 3,3 & \\
\hline Otros familiares & 12 & 3,7 & 5 & 1,5 & 7 & 2,2 & \\
\hline Piso compartido & 5 & 1,5 & 2 & 0,6 & 3 & 0,9 & \\
\hline Piso tutelado & 3 & 0,9 & 2 & 0,6 & 1 & 0,3 & \\
\hline No contestaron & 27 & 8,2 & 14 & 4,3 & 13 & 3,9 & \\
\hline Total & 328 & 100,0 & 163 & - & 165 & - & \\
\hline
\end{tabular}

* $p>0,001$

Fuente: Elaboración propia. 
Las personas encuestadas convivían principalmente con la pareja o los hijos (37,5\%), o con los padres o hermanos (39\%), es decir, con la familia próxima. Un $9,1 \%$ vivía solo/a, y una pequeña parte de la muestra lo hacía en piso compartido $(1,5 \%)$ o en piso tutelado (0,9\%) (tabla 4).

En cuanto al nivel de estudios, más de la mitad de tenía estudios primarios (65,2\%), un $17 \%$ había cursado Formación Profesional y un $4,9 \%$ no tenía estudios. No existían diferencias entre hombres y mujeres en el ámbito formativo. Respecto a la procedencia, el $70,7 \%$ de la muestra (232 personas) había nacido en Gipuzkoa, el 20,1\% (66 personas) en otras provincias y un $4,6 \%$ era inmigrante (tabla 5 ).

\subsection{Tipo y grado de minusvalía}

El 32\% de la muestra (106 personas) presentaba una minusvalía física, dificultades motoras, fisiológicas o funcionales. Un $\mathbf{2 9 , 9 \%}$ (98 personas) tenía una discapacidad intelectual, con un funcionamiento intelectual inferior a la media. El $23,7 \%$ (78 personas) estaba afectada por enfermedad mental (esquizofrenia, trastorno bipolar, trastorno de la personalidad, trastornos depresivos o ansiosos crónicos). En cuanto a minusvalía sensorial, el 10,7\% de la muestra padecía una discapacidad auditiva, mientras que el 3,4\% presentaba una discapacidad visual. Respecto al grado de minusvalía, el $62,8 \%$ (207 personas) tenía un grado de entre el $33 \%$ y el $44 \%$, siendo igual entre hombres y mujeres. El 23,7\% tenía un grado de minusvalía de entre el 45 y el $64 \%(10,9 \%$ hombres y $12,8 \%$ mujeres).

\subsection{Características laborales}

Las personas encuestadas llevaban una media de 10,33 años trabajando en la empresa (desviación típica: 7,60), con un rango de entre 1 y 30 años. El $97 \%$ tenía jornada a tiempo completo. Los trabajadores pertenecían a seis categorías laborales ${ }^{2}$. La mayoría de la muestra (32,3\%) estaba compuesta por operarios que realizaban mano de obra directa sin supervisión en tareas habituales, o con supervisión esporádica en tareas nuevas, y tenían una elevada autonomía. El 31,4\% eran personas que realizaban con calidad tareas repetitivas con supervisión esporádica, pero que necesitaban ayuda en tareas nuevas. El 16,4\% eran trabajadores con limitada autonomía que requerían supervisión continua y realizaban tareas operativas sencillas y repetitivas. Los encarga-

2 Las categorías laborales de esta empresa son, de menor a mayor rango: operario (cuatro subcategorías diferentes, dependientes del grado de autonomía o la supervisión requerida -entre otros factores-y acorde con el salario), encargados y personal de la estructura organizativa. dos suponían un $11,2 \%$ de la muestra, y realizaban tareas de intermediación entre los operarios y las personas de la estructura organizativa. Por último, los operarios de mayor autonomía sumaban el 6,4\% de la muestra y eran capaces de realizar tareas productivas con una calidad alta y organizar su trabajo en ausencia del encargado. Un $2 \%$ de la muestra pertenecía a la estructura organizativa (administrativos y coordinadores, entre otros cargos).

Respecto al tipo de contrato, el 67,7\% de las personas encuestadas tenían un contrato indefinido a tiempo completo: el 35,7\% eran mujeres, y el $32 \%$, hombres. El 28,9\% tenía un contrato de duración determinada a tiempo completo, siendo mayor el número de hombres con este tipo de contrato $(16,7 \%)$ que el de mujeres (12,2\%). Sólo ocho personas $(2,4)$ tenían un contrato de duración determinada a tiempo parcial: dos hombres $(0,6 \%)$ y seis mujeres (1,8\%). Pocos tenían un contrato indefinido a tiempo parcial (0,9\%), de los cuales uno era hombre, y dos, mujeres.

\subsection{Satisfacción laboral general}

El nivel de satisfacción general era medio-alto. Teniendo en cuenta las puntuaciones por subescalas, la de organización es la que mayor puntuación recibe, seguida de la de relaciones laborales, mientras que la subescala de condiciones laborales obtiene la menor puntuación.

Por ítems, la mejor puntuación $(3,49)$ se registra en lo que se refiere a la finalidad de la empresa, esto es, los/as trabajadores/as se mostraban satisfechos con el hecho de que el principal objetivo de la empresa fuera la contratación de personas con minusvalía. Le sigue la satisfacción con el centro de trabajo $(3,22)$. Las puntuaciones más bajas corresponden a la satisfacción respecto al salario $(2,00)$ y al uniforme $(2,34)$, con puntuaciones próximas al 'poco satisfecho/a'.

\subsection{Satisfacción laboral en función del sexo}

En la tabla 7, se muestran los ítems donde han aparecido diferencias significativas en el nivel de satisfacción laboral entre hombres y mujeres. En general, las mujeres se mostraban más satisfechas con su trabajo, excepto en la condición física que requería su trabajo, donde los hombres estaban más satisfechos.

\subsection{Satisfacción laboral en función de la categoría laboral}

Para los análisis de datos en función de la categoría laboral, se realizaron pruebas "F" ANOVA de un factor, con la prueba post-hoc HSD de Tukey. 
Tabla 6. Nivel de satisfacción laboral, por subescalas

Condiciones materiales

Facilidad para llegar al trabajo

Condiciones del entorno laboral

Medios para reducir el riesgo de accidentes

Maquinaria y utensilios

Modo en el que los compañeros dejan el material

Uniforme

Total subescala

Condiciones laborales

Horario

Calendario

Vacaciones

Salario

Esfuerzo físico requerido para la tarea

Condición física

Tiempo para la realización del trabajo

Oportunidad de promoción

Total subescala

Relaciones laborales

Ambiente del trabajo

Relación con los compañeros

Compañerismo

Relación con el coordinador

Relación con el encargado

Grado en el que el encargado motiva

Grado en el que el encargado respeta

Grado en el que el encargado organiza

Grado en el que el encargado fomenta la participación

Grado en el que el encargado colabora

Grado en el que el encargado muestra flexibilidad

Total subescala

Promoción y desarrollo personal

Formación recibida

Aprovechamiento de la formación

Total subescala

Organización

Centro de trabajo

Empresa

Finalidad de la empresa

Total subescala

Información

Vías de comunicación con la dirección

Gestión de quejas

Vías de información empresa-trabajador

Comunicación en el grupo trabajo

Total subescala

Satisfacción general

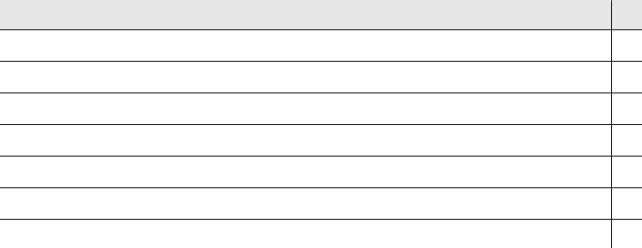

\begin{tabular}{c|c}
$\bar{\chi}$ & $\alpha$ \\
\hline 3,21 & 0,73 \\
\hline 2,88 & 0,76 \\
\hline 3,17 & 0,69 \\
\hline 3,20 & 0,67 \\
\hline 2,82 & 0,85 \\
\hline 2,34 & 1,04 \\
\hline 2,94 & 0,79 \\
\hline
\end{tabular}

\begin{tabular}{l|l}
3,16 & 0,77
\end{tabular}

\begin{tabular}{l|l}
2,95 & 0,77 \\
\hline & 0,86
\end{tabular}

\begin{tabular}{l|l}
3,11 & 0,8
\end{tabular}

2,00

2,75

3,09

2,91

2,61

2,82

0,81

0,94

0,83

0,72

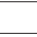

0,8

0,99

\begin{tabular}{l|l}
3,14 & 0,73 \\
\hline 3,20 & 0,72
\end{tabular}

3,20

3,07

0,72

0,79

3,16

0,75

0,63

\begin{tabular}{l|l}
3,11 & 0,83
\end{tabular}

\begin{tabular}{l|l}
3,11 & 0,83 \\
3,22 & 0,72
\end{tabular}

\begin{tabular}{l|l}
3,26 & 0,67
\end{tabular}

3,26

3,26

3,31

3,17

3,21

0,67

0,68

0,69

0,75

0,72

\begin{tabular}{l|l}
3,11 & 0,72
\end{tabular}

\begin{tabular}{l|l}
3,11 & 0,72 \\
3,20 & 0,77
\end{tabular}

3,16

0,75

Fuente: Elaboración propia.

Tabla 7. Principales diferencias entre hombres y mujeres en lo que se refiere a la satisfacción laboral

\begin{tabular}{|c|c|c|c|c|c|c|}
\hline \multirow[t]{2}{*}{ Subescala } & \multirow[t]{2}{*}{ Ítem } & \multicolumn{2}{|c|}{$\begin{array}{l}\text { Hombres } \\
(\mathrm{N}=163)\end{array}$} & \multicolumn{2}{|c|}{$\begin{array}{c}\text { Mujeres } \\
(\mathrm{N}=165)\end{array}$} & \multirow[t]{2}{*}{$t$} \\
\hline & & $\bar{\chi}$ & $\alpha$ & $\bar{\chi}$ & $\alpha$ & \\
\hline \multirow{3}{*}{$\begin{array}{l}\text { Condiciones } \\
\text { materiales }\end{array}$} & Facilidad para llegar al puesto de trabajo & 3,12 & 0,80 & 3,30 & 0,65 & $-2,23^{*}$ \\
\hline & Medios para reducir los accidentes & 3,07 & 0,68 & 3,27 & 0,69 & $-2,60^{*}$ \\
\hline & Maquinaria y utensilios & 3,11 & 0,65 & 3,27 & 0,67 & $-2,47^{\star}$ \\
\hline \multirow{4}{*}{$\begin{array}{l}\text { Condiciones } \\
\text { laborales }\end{array}$} & Vacaciones & 3,00 & 0,88 & 3,22 & 0,72 & $-2,42^{\star}$ \\
\hline & Salario & 1,87 & 0,89 & 2,13 & 0,96 & $-2,54^{*}$ \\
\hline & Esfuerzo físico requerido & 2,84 & 0,74 & 2,66 & 0,90 & $2,03^{*}$ \\
\hline & Oportunidad de promoción & 2,38 & 1,07 & 2,70 & 1,04 & $-2,54^{*}$ \\
\hline \multirow{5}{*}{$\begin{array}{l}\text { Relaciones } \\
\text { laborales }\end{array}$} & Relación con el coordinador & 3,03 & 0,72 & 3,29 & 0,77 & $-3,01^{\star *}$ \\
\hline & Grado en el que el encargado organiza & 3,18 & 0,63 & 3,34 & 0,71 & $-2,08^{*}$ \\
\hline & Grado en el que el encargado fomenta la participación & 3,18 & 0,64 & 3,34 & 0,71 & $-2,08^{*}$ \\
\hline & Grado en el que el encargado colabora & 3,21 & 0,69 & 3,41 & 0,67 & $-2,40^{*}$ \\
\hline & Grado en el que el encargado muestra flexibilidad & 3,08 & 0,69 & 3,26 & 0,80 & $-2,11^{*}$ \\
\hline \multirow[t]{2}{*}{ Promoción } & Formación recibida & 3,01 & 0,70 & 3,20 & 0,71 & $-2,37^{\star}$ \\
\hline & Aprovechamiento de la formación & 3,09 & 0,76 & 3,31 & 0,76 & $-2,59^{*}$ \\
\hline \multirow{2}{*}{$\begin{array}{l}\text { Información, } \\
\text { comunicación }\end{array}$} & Gestión de quejas & 2,81 & 0,83 & 3,01 & 0,86 & $-2,07^{*}$ \\
\hline & Vías de información empresa-trabajador & 2,96 & 0,72 & 3,17 & 0,78 & $-2,43^{*}$ \\
\hline
\end{tabular}

${ }^{*} p<0,05 .{ }^{* *} p<0,01$.

Fuente: Elaboración propia. 


\begin{tabular}{|c|c|c|c|c|c|c|c|c|c|c|c|c|c|c|}
\hline \multirow[t]{4}{*}{ Subescala } & \multirow[t]{4}{*}{ Ítem } & \multicolumn{12}{|c|}{$\begin{array}{c}\text { Categoría laboral } \\
\text { (de menor a mayor rango) }\end{array}$} & \multirow[t]{4}{*}{$\boldsymbol{F}$} \\
\hline & & \multicolumn{8}{|c|}{ Operarios } & \multicolumn{2}{|c|}{ Encargados } & \multicolumn{2}{|c|}{ Estructura } & \\
\hline & & \multicolumn{2}{|r|}{1} & \multicolumn{2}{|c|}{ C } & \multicolumn{2}{|c|}{ B } & \multicolumn{2}{|c|}{ A } & & & & & \\
\hline & & $\bar{\chi}$ & $\alpha$ & $\bar{\chi}$ & $\alpha$ & $\bar{\chi}$ & $\alpha$ & $\bar{\chi}$ & $\alpha$ & $\bar{\chi}$ & $\alpha$ & $\bar{\chi}$ & $\alpha$ & \\
\hline \multirow[t]{3}{*}{$\begin{array}{l}\text { Condiciones } \\
\text { materiales }\end{array}$} & Medios para reducir los accidentes & 3,14 & 0,73 & 3,02 & 0,67 & 3,25 & 0,70 & 3,04 & 0,80 & 3,43 & 0,55 & 3,28 & 0,48 & $\begin{array}{c}2,42^{*} \\
5>2\end{array}$ \\
\hline & Maquinaria y utensilios & 3,27 & 0,68 & 3,12 & 0,65 & 3,19 & 0,68 & 3,33 & 0,57 & 3,40 & 0,59 & 2,42 & 0,78 & $\begin{array}{c}3,21^{\star *} \\
1,3,4,5^{>6}\end{array}$ \\
\hline & Uniforme & 2,69 & 0,97 & 2,38 & 0,97 & 2,33 & 1,17 & 2,04 & 0,86 & 1,88 & 0,93 & 2,5 & 0,57 & $\begin{array}{c}3,03^{*} \\
1>5\end{array}$ \\
\hline \multirow[t]{5}{*}{$\begin{array}{l}\text { Condiciones } \\
\text { laborales }\end{array}$} & Calendario & 3,11 & 0,81 & 2,93 & 0,81 & 2,89 & 0,92 & 2,47 & 0,98 & 3,08 & 0,73 & 3,57 & 0,68 & $\begin{array}{l}2,66^{*} \\
1,6>4\end{array}$ \\
\hline & Vacaciones & 3,38 & 0,52 & 3,05 & 0,78 & 3,07 & 0,89 & 2,61 & 0,97 & 3,18 & 0,81 & 3,57 & 0,78 & $\begin{array}{c}3,54^{\star \star} \\
1>4 \\
\end{array}$ \\
\hline & Salario & 1,98 & 1,01 & 1,91 & 0,91 & 1,99 & 0,91 & 1,61 & 0,74 & 2,40 & 0,89 & 3,00 & 0,81 & $\begin{array}{c}4,00 * \star \\
6>1,4\end{array}$ \\
\hline & Tiempo para la realización del trabajo & 3,18 & 0,67 & 2,88 & 0,74 & 2,90 & 0,80 & 2,50 & 0,88 & 2,91 & 0,75 & 2,71 & 0,75 & $\begin{array}{c}2,65^{*} \\
1>4 \\
\end{array}$ \\
\hline & Oportunidad de promoción & 2,33 & 0,99 & 2,47 & 0,96 & 2,83 & 0,98 & 2,25 & 1,06 & 2,94 & 0,95 & 2,85 & 0,37 & $\begin{array}{c}3,72^{\star \star} \\
3,5^{\prime 1}\end{array}$ \\
\hline
\end{tabular}

* $p<0,05^{* *} p<0,01{ }^{* * \star} p<0,001$

Fuente: Elaboración propia.

Se han encontrado diferencias significativas en la subescala de condiciones materiales en los ítems 'medios que se te dan para reducir el riesgo de accidentes', 'maquinaria y 'uniforme'. En general, se mostraban más satisfechos los trabajadores con la categoría de encargado, a excepción de lo referido al uniforme. En la subescala de condiciones laborales, por su parte, se han hallado diferencias significativas en los ítems ‘calendario', 'vacaciones', 'salario', 'tiempo que se te da para realizar tu trabajo' y 'oportunidad de promoción existente', siendo, en general, los trabajadores con mayor categoría salarial los menos satisfechos, y los operarios de menor categoría salarial, los que más, a excepción de los ítems ‘salario' y ‘oportunidad de promoción', en los que comparten su insatisfacción con los de mayor categoría salarial. No se han encontrado diferencias significativas en función de la categoría laboral en ninguna otra subescala de la encuesta.

\subsection{Satisfacción laboral en función del tipo de minusvalía}

Respecto a la satisfacción laboral, no se han encontrado diferencias estadísticamente significativas en función del tipo de minusvalía.

\section{Conclusiones y discusión}

En los escasos estudios sobre la calidad de la vida laboral de trabajadores con discapacidad intelectual, se analizan las variables que inciden en esta variable. En otras investigaciones, se analizan las diferencias de satisfacción laboral dependiendo del tipo de empleo, comparando el empleo protegido con el empleo en empresa ordinaria (Kober, 2010), y el empleo con apoyo con el empleo sin apoyo (Parent, Kregel y Johnson, 1996). En otros trabajos donde se compara la satisfacción laboral entre personal discapacitado y no discapacitado (Malo y Pagán, 2009; Renaud, 2002; Uppal, 2005), los resultados son contradictorios, en ocasiones a favor de los no discapacitados, aunque en otros casos se han encontrado resultados similares entre ambos grupos (Laschinger, Wong y Greco, 2006; Leiter y Laschinger, 2006; Tuuli y Karisalmi, 1999).

Comparando el estudio realizado aquí con otras investigaciones, se observan resultados similares en cuanto a satisfacción laboral en personas con discapacidad, aunque los datos sociodemográficos sean diferentes de un estudio a otro. En el estudio de Flores et al. (2010), por ejemplo, son 427 personas con discapacidad intelectual (262 hombres y 165 mujeres), la mayoría de entre 31 y 40 años, con contratos a tiempo completo y un promedio de 11 años trabajando. En otros estudios, la muestra es más reducida (De Jesús, Girón y García, 2005), siendo 50 sujetos (26 hombres y 24 mujeres), de entre 18 y 25 años y con un promedio de tres años trabajados.

Respecto a las hipótesis planteadas en este estudio, en general, el nivel de satisfacción con el trabajo es medio-alto, lo que confirma nuestra primera hipótesis. En los estudios llevados a cabo por De Jesús, Girón y García (2005) y por Flores et al. (2010), los resultados revelan asimismo un promedio alto en calidad de vida laboral en personas con discapacidad intelectual. En el Hansen y Nielsen (2008), por su parte, también se obtienen resultados de alta satisfacción en personas con discapacidad, en comparación con personas sin discapacidad; y en el de McAfee (1986), y McAfee y McNaughton (2007), aparecen grados altos y moderados, respectivamente, 
de satisfacción laboral general en personas con discapacidad. Otras investigaciones, como la de Quigley (1968), revelan que aproximadamente el 60\% de los sujetos con deficiencia auditiva están satisfechos con su trabajo, mientras que en la de Hardy (1968), más del $60 \%$ de las personas con discapacidad intelectual refieren estar satisfechas con su trabajo. Los ítems que menos puntuación han obtenido en cuanto a la satisfacción son el salario y uniforme. En el estudio realizado por McAfee y McNaughton (2007), los trabajadores con discapacidad muestran una fuerte insatisfacción también hacia el salario, al igual que en el de Houser y Chace (1993).

En cuanto a la satisfacción laboral en función del sexo, las mujeres se encuentran más satisfechas que los hombres, lo cual refuta nuestra segunda hipótesis, en la que no se predecían diferencias en la satisfacción laboral en función del sexo. Los resultados de nuestro estudio difieren de otros, como el de Malo y Pagán (2009), donde se observa que las mujeres con discapacidad presentan menores índices de satisfacción laboral que los hombres con discapacidad, al igual que en el estudio de Burke (1999). La menor satisfacción de los hombres de nuestra muestra con el trabajo puede ser debida a que las tareas que realizan son de limpieza industrial, un trabajo que ha sido asociado históricamente al rol femenino.

Teniendo en cuenta la categoría laboral, en general las personas con categorías que requieren menos autonomía, menos responsabilidades y salarios más bajos se muestran más satisfechas que las de aquellas categorías que requieren más autonomía, y responsabilidad y salarios más altos. Nuestra cuarta hipótesis no se cumple en este caso, ya que las personas de mayor categoría laboral no se encuentran más satisfechas, sino que ocurre prácticamente lo contrario. En el estudio de Malo y Pagán (2009), se concluye que no hay diferencias significativas entre las personas con discapacidad y escala de ocupación: a mayor puesto de responsabilidad, mayor satisfacción, y viceversa. En el caso de la muestra aquí estudiada, pensamos que las personas de la categoría 'superior' (con mayor responsabilidad), se puedan sentir menos satisfechas debido a que, siendo similares las tareas que realizan a las de un encargado, no tienen esa consideración, ni su salario, mientras que los operarios con categoría 'inferior' (con menor responsabilidad), pueden sentirse más satisfechos por el tipo de tareas que realizan y por ver mayor probabilidad de promoción a categorías superiores.

No se han encontrado diferencias significativas entre los trabajadores con diferentes minusvalías. Esto es, no hay ningún colectivo que se muestre más satisfecho o menos satisfecho, no existen diferencias entre las personas con discapacidad física, intelectual, sensorial, ni con enfermedad mental. Esto también se observa en el estudio de Judd (1981), aunque la muestra utilizada en él estaba constituida por personas con discapacidades del desarrollo. En nuestro caso, tampoco se cumple nuestra quinta hipótesis, que preveía diferencias en función del tipo de discapacidad.

A partir de los resultados obtenidos en este estudio, se podrían marcar líneas de trabajo, comparando los niveles de satisfacción entre trabajadores que realizan diferentes actividades, como jardinería, hostelería o lavandería. Sería importante también poder comparar la satisfacción de trabajadores con y sin discapacidad en las mismas tareas y en empresas ordinarias.

Entre las limitaciones que presenta este estudio, cabe destacar no haber utilizado una herramienta de recogida de datos estandarizada, ni adaptada al colectivo con discapacidad intelectual, aspecto que, en estudios posteriores, podría tenerse en cuenta.

El objetivo principal de este estudio residía en conocer la satisfacción laboral de las personas con discapacidad e identificar aspectos de mejora en el trabajo que desempeñan. Tras los resultados, se han puesto en marcha grupos de trabajo con el fin de aumentar la satisfacción de los y las trabajadores y trabajadoras de este centro especial de empleo. 


\section{Bibliografía}

(1982) “Ley 13/1982, del 7 de abril, de Integración Social de Minusválidos", Boletín Oficial del Estado, no 130,30 de abril de 1982.

ALOMAR, E.; y CABRÉ, M. (2005): “El trabajo de jóvenes con discapacidad intelectual en entornos normalizados", Revista Síndrome de Down, ํㅡ 22, págs. 118-124.

BURKE, R. J. (1999): “Disability and women's work experiences: An exploratory study", International Journal of Sociology and Social Policy, vol. 19, no 12 , págs. 21-33.

DE JESÚS, A.; GIRÓN, I.; y GARCÍA, G. (2005): "Relación entre la modalidad de empleo y el nivel de calidad de vida laboral de personas con discapacidad intelectual leve", Nómadas. Revista Crítica de Ciencias Sociales y Jurídicas, ํㅡ 22, págs. 333-381.

FLORES, N. et al. (2010): "Análisis de la calidad de vida laboral en trabajadores con discapacidad", Zerbitzuan, no 47, págs. 95-107 [disponible en <http://www.zerbitzuan.net/documentos/zerbitzuan/Analisis\%2ocalidad\%20de\%2ovida \%2olaboral.pdf $>$.

HANSEN, N. y NIELSEN, H. O. (2008): Disabilities and employment in 2006. Terms and conditions for disabled people in the labour market, Copenhague, Danish National Centre for Social Research.

HARDY, M. (1968): “Disabled readers: What happens to them after elementary school?", Canadian Education and Research Digest, $\mathrm{n} \times \mathbf{0}$, págs. 338-346.
HOUSER, R.; y CHACE, A. (1993): “Job satisfaction of people with disabilities placed through a project with industry", Journal of Rehabilitation, en-mar.

KOBER. R. (2010): Employment for People with Intellectual Disabilities: The effect of Different Methods of Employment on Job Satisfaction and Quality of Life, Saarbrücken, VDM Verlag Dr. Müler.

LASCHINGER, H. K. S.; WONG, C. A.; y GRECO, P. (2006): "The impact of staff nurse empowerment on person-job fit and work engagement/burnout”, Nursing Administration Quarterly, no 30 , págs. 358-367.

LEITER, M. P.; y LASCHINGER, H. K. S. (2006): "Relationships of work and practice environment to professional burnout", Nursing Research, nํㅜ 55, págs. 137-146.

MALO, M. A.; y PAGÁN, R. (2009): "Job satisfaction and disability", Spanish Economic Review, nํㅜ 11, págs. 51-74.

MCAFEE, J. (1986): "The handicapped worker and job satisfaction", Vocational Evaluation and Work Adjustment Bulletin, no 19, págs. 23-27.

-; y MCNAUGHTON, D. (2007): “Transitional outcomes: Job satisfaction of workers with disabilities, part two. Satisfaction with promotions, pay, coworkers, supervision, and work conditions", Journal of Vocational Rehabilitation, $\mathrm{n} \div 8$, págs. 243-51.

NEZU, C. M.; NEZU, A. M.; y DELLICARPINI, L. (1997): “Tratamiento ambulatorio para personas con retraso mental”, en CABALLO, V. (dir.): Siglo XXI. 
A halik eta aditu eta profesional gehienen eskura jartzearren, interes nabarmena duten bi testu helarazten ditu jarraian Zerbitzuan aldizkariak, eta egoitza-zentro handiekin alderatuta bizitoki komunitarioek urrituentzat dituzten abantailak aldezten dira bietan.

Lehenengo idazkian pertsona hauentzako egoitzazerbitzuen gainean hainbat hamarkadatan egindako ikerketa konparatuak sortu duen ezagutza gainbegiratzen da, eta ondorioztatzen da nahiko agerikoa dela bizitoki komunitarioek, behar bezala kudeatzen badira, bizi-kalitate handiagoa ziurtatzen dutela. Testua Journal of Intellectual Disability Research aldizkari entzutetsuan argitaratu zen eta Ezgaitasun Intelektualen Azterketa Zientifikorako Nazioarteko Elkarteko (IASSID) Politika eta Praktika Konparatiboen Ikerketa Taldeko kideek gauzatu zuten. Adierazitako erakundeak bere adierazpentzat hartu zuen.

Bigarren artikulua lehenengoaren osagarria da, eta egoitza-zentro handien ordez pixkana bizitoki komunitarioak jartzeko jarraitu behar diren printzipioak adierazten dira bertan. Kasu honetan txostena hainbat erakundetako aditu-talde batek prestatu du eta Europar Batzordeko Enplegua, Gizarte Gaiak eta Aukera Berdintasunerako Zuzendaritza Nagusiak argitaratu du. Edukia prestatzeko gaiari buruz dagoen literatura aztertu da eta hurbileko egoitza-zentroetako jardunbide egokiak identifikatu dira.
C on el fin de ponerlos al alcance del mayor número de especialistas y profesionales, la revista Zerbitzuan reproduce seguidamente dos textos de notable interés, que defienden las ventajas de los alojamientos comunitarios para personas con discapacidad frente a los grandes centros residenciales.

El primero de los escritos repasa el conocimiento generado a lo largo de varias décadas de investigación comparada sobre los servicios residenciales para estas personas, y concluye que existen evidencias suficientes de que los alojamientos comunitarios, si se gestionan de modo adecuado, garantizan una mayor calidad de vida. El texto, publicado en la prestigiosa Journal of Intellectual Disability Research, fue elaborado por miembros del Grupo de Investigación sobre Política y Práctica Comparativas, de la Asociación Internacional para el Estudio Científico de las Discapacidades Intelectuales (IASSID), entidad que lo adoptó como una declaración propia.

El segundo artículo es complementario del anterior, en la medida en que señala los principios que deben guiar la progresiva sustitución de los grandes centros residenciales por alojamientos en la comunidad. En este caso, se trata de un informe preparado por un grupo de expertos/as de diferentes instituciones, y editado por la Dirección General de Empleo, Asuntos Sociales e Igualdad de Oportunidades de la Comisión Europea. Para su redacción, se ha consultado la literatura existente sobre la materia y se han identificado buenas prácticas en servicios residenciales de proximidad. 